\title{
Employee Anonymous Online Dissent: Dynamics and Ethical Challenges for Employees, Targeted Organisations, Online Outlets, and Audiences
}

\author{
Silvia Ravazzani
}

Aarhus University

Alessandra Mazzei

IULM University

\begin{abstract}
This article aims to enhance understanding of employee anonymous online dissent (EAOD), a controversial phenomenon in contemporary digital environments. We conceptualise and scrutinise EAOD as a communicative and interactional process among four key actors: dissenting employees, online outlet administrators, audiences, and targeted organisations. This multi-actor, dialectical process encompasses actor-related tensions that may generate unethical consequences if single voices are not brought out and confronted. Appropriating a Habermasian ethical and discursive lens, we examine and disentangle three particular challenges emerging from the EAOD process: lack of accountability and potential opportunism; equal participation and resolution of actor-related tensions; and organisational participation and internalisation of dissent. We show that EAOD can initiate plural dialogue that helps co-construct and balance different voices within an informal and noninstitutionalised context for interaction and public deliberation. We conclude our inquiry by offering reflections on practical implications and a research agenda for further investigation.
\end{abstract}

KEY WORDS: employee displaced dissent, online anonymous communication, polyphony, Habermas, deliberative discourse

7 mployee anonymous online dissent (EAOD) is an emerging and controversial - phenomenon in contemporary digital environments. The recent case of Amazon is emblematic of this practice: in August 2015, the New York Times published a devastating exposé depicting Amazon as an exploitative and soulless workplace (Kantor \& Streitfeld, 2015), and this was rapidly echoed by dozens of stories publicly reported by dissatisfied employees, anonymously or pseudonymously, on confessions pages and review websites like Reddit and Glassdoor. The online debate involved the juxtaposition of employee voices pro and against Amazon and took place in full view of online audiences also participating in the debate. This case is also exemplary because the founder and chief executive of Amazon acknowledged 
these dissenting voices uttered publicly online, and encouraged employees to contact him directly and disclose unethical practices (Streitfeld \& Kantor, 2015). As a general trend, news media and less institutionalised online spaces increasingly enable individuals, including employees, to actively voice dissent in public fora (e.g. the exposé published by The New York Times received almost 6,000 comments in one week), often in anonymous ways.

In scholarly literature, employee voice and-in particular—dissenting voice are becoming some of the most debated issues of organisation business ethics (Castelló, Morsing, \& Schultz, 2013; Trittin \& Schoeneborn, 2015; Whelan, 2013), given that "work is a place where many adults devote significant portions of their waking lives, but it is also a place where civil liberties, including but not limited to freedom of speech, are significantly constrained" (Barry, 2007: 264). Dissensual voices are frequently discouraged in the workplace or entrapped in espoused voice systems disconnected from actual processes and changes, and their expression often leads to retaliation (Bishop \& Levine, 1999; Kassing, 1997). So far, existing research has overlooked the expression of employee dissent outside organisations (Barry, 2007), in particular via online public outlets where safer anonymous disclosure can take place and a larger audience can be reached (Balnave, Barnes, Macmillan, \& Thornthwaite, 2014; Gossett \& Kilker, 2006). We argue that EAOD connects four key actors: not only employees and their organisations, but also administrators of online outlets hosting employee dissent and online audiences reading and participating in such online discussions (e.g. former employees and consumers). Although we acknowledge the role that other actors might play in EAOD, for example regulators and civil society collective actors like non-governmental organisations, we decided to limit the scope of our present discussion to these four key actors who are more directly involved in the phenomenon of EAOD. With this choice of actors, we furthermore intend to stress the unprecedented role the Internet plays, not only in providing new and varied sources of information, but also in increasing the power of individual citizens and digital media actors (Castells, 2007; Whelan, Moon, \& Grant, 2013), and in creating opportunities for deliberative discourse within more informal and noninstitutionalised contexts (Baur \& Arenas, 2014).

While the relevance of EAOD continues to grow in actual practice, academic investigation remains lacking and, in addition, inattentive to the important ethical aspects involved. From a broader ethical standpoint, articulating marginal and dissensual voice is part of the basic human right to practice freedom of expression (Kassing, 2011), and its recognition promotes basic human values such as dignity, integrity, and individual conscience (Shahinpoor \& Matt, 2006). Moreover, employee dissent is often — but not exclusively — ethically motivated (Shahinpoor \& Matt, 2006), e.g., responding to unfair treatment and whistleblowing (Miceli, Near, \& Dworkin, 2008) or opposing corporate social irresponsibility (Stohl, Etter, Banghart, \& Woo, 2017). On the other hand, dissenting communicative behaviours encompass a number of dilemmas, given that along with rights of freedom of speech and collective information sharing about work conditions come communicative responsibilities such as honesty and accountability (Stohl et al., 2017). In reality, self-centred and opportunistic behaviours (Castelló et al., 2013; Krishna \& Kim, 2015) may threaten the potential 
value of dissent inherent in its open expression and negotiation. In addition, online disclosure creates a blurring of boundaries and circularity of effects between work and private life (Stohl et al., 2017). In practice, targeted managers and organisations may disregard employee dissent or even interpret it as an unfair and harmful burden, with dissenters often being punished (Shahinpoor \& Matt, 2006).

Acknowledging the contemporary and ethical relevance of EAOD, we delve into this under-researched phenomenon in order to offer enhanced awareness of the complexity and challenges it brings about. More specifically, our investigation is guided by the following research questions: what are the actor-related tensions, communicative behaviours, and outcomes that make up the EAOD communicative and interactional process? And how can this multi-actor, dialectical process be actualised in a responsible way through deliberative discourse?

The article is structured as follows. In the first section, we set out the background by discussing the three central notions of dissent, anonymous communication, and online communication. In the second section, we reorganise the insights from the reviewed literature to develop a multi-actor, dialectical model of the EAOD communicative process, making explicit the complexity of actor-related tensions, communicative behaviours, and outcomes, and pointing out the challenges this complexity creates for a responsible actualisation of EAOD. In the third section, we appropriate a Habermasian ethical and discursive lens to address such challenges, and show how deliberative discourse can release the value inherent in dissensual, anonymous, online voice through interaction and balancing across actors in practical discourse. Based on this, we also suggest implications relevant to practice. In the concluding section, we summarise the key contributions of the article and detail future research directions.

\section{ESTABLISHING THE BACKGROUND: DISSENT, ANONYMITY, AND ONLINE COMMUNICATIVE ENVIRONMENT}

In this section, we set out the backbone of our conceptual inquiry by illustrating and connecting the three notions of dissent, anonymity, and communication in the contemporary online environment. Insights from these three broader areas of literature are essential given the scarce existing research dedicated to EAOD. In doing so, we situate our work at the interconnection of these areas, and draw on them to argue for the importance and complexity of employee dissensual and anonymous voice and its expression in digital environments.

\section{Understanding and Building on Dissent Literature: The Value of Dissenting Voice Vis-À-Vis Consensus}

Scholars in the areas of business ethics have recently started emphasising the value and constructive role of dissent vis-à-vis consensus (e.g. Castelló et al., 2013; Dawkins, 2015; Scherer \& Palazzo, 2007; Whelan, 2013). Traditionally, the importance of dissent has been underplayed in literature in favour of more consensusfocused models founded on "processes of discursive or reasoned accordance between corporations and civil society" (Whelan, 2013: 755). Dissensual voice has been 
depicted as something to defy or avoid, shadowed by the threats of destructive and opportunistic behaviours (Klaas, Olson-Buchanan, \& Ward, 2012) and dysfunctional conditions for organisations (Kassing, 2011).

Yet, as Kassing (2011) intriguingly points out, the practice of seeking and appreciating dissent has a fairly long history, from the dedicated procedures of the UK Parliament House of Lords already established in the sixteenth century and the US Supreme Court at the beginning of the twentieth, to the more recent phenomenon of whistleblowing (Miceli et al., 2008). The relevance and value of dissent for the healthy functioning of institutions and society in general, and for ethically responsible organisations in particular, are embodied by its inherent potential for questioning the status quo and improving existing practices and structures (Dawkins, 2015; Kassing, 2011; Shahinpoor \& Matt, 2006; Whelan, 2013). This emerging view carries with it the idea that polyphonic and dissensual voices can contribute to solve problems in society, rather than being suppressed, integrated into one monophonic voice, or dominated by another homophonic voice (Christensen, Morsing, \& Cheney, 2008).

Consistent with the traditional emphasis on consensus, specific interest in employee dissent has been overlooked in literature, although it has been portrayed as an important mechanism for enhancing employee sense of control and feeling of being valued and for generating organisational positive change and learning (Deetz, 1998). Much of the existing research in this area has, over the years, more explicitly addressed the topics of constructive voice and silence within organisations (Morrison, 2011). Also in practice, the value of dissent seems underestimated in organisations, which strive to maintain a monological and hegemonic narrative, leaving little room for competing discourses and interpretations (Christensen et al., 2008). In many cases, organisations lack internal policies and tools for soliciting and expressing employee dissent, or they employ espoused participatory mechanisms aimed at control (Kassing, 1997, 2011). This creates a paradox of homogeneity where diversity of opinion is being preached but preference is accorded to consensus and agreement (Stohl \& Cheney, 2001).

So far, Kassing is the scholar who most extensively researched employee dissent, which he defines as the act of "expressing disagreement or contradictory opinions about organisational practices, policies and operations" (1998: 183). Research on this phenomenon has explored different aspects of employee dissent: triggering events, such as employee treatment and ethically questionable corporate decisions (Kassing \& Armstrong, 2002); determinants of the decision whether to express dissent and in what form, i.e. organisational (e.g., climate for voice, dedicated procedures), relational (e.g., supervisor relationship quality, perceived risk of retaliation), and individual (e.g., satisfaction, trait-like characteristics such as self-esteem and assertiveness) (Kassing, 1998, 2011; Klaas et al., 2012); forms of dissenting, i.e. upward with management, lateral with co-workers, and displaced with friends, family, or others outside the workplace (Kassing, 2011); goals, i.e. prosocial to benefit the organisation, revenge-oriented to seek personal retribution, and mixed (Klaas et al., 2012); and content of dissent messages, such as solution presentation, humour, and venting frustrations (Garner, 2009). 
Existing research has privileged the exploration of dissent within organisations (i.e. expressed to management and co-workers) or in the specific form of whistleblowing (Miceli et al., 2008), whereas much remains unexplored in regard to more covert practices (Teo \& Caspersz, 2011) and, in particular, dissent displaced outside the workplace (Barry, 2007). In addition, existing research has mainly investigated identified employee voice (Klaas et al., 2012), despite the fact that anonymous input has been indicated as highly relevant in the case of employee dissent (Bishop \& Levine, 1999; Scott \& Rains, 2005). Based on these important knowledge gaps, our inquiry focuses on employee displaced dissent in anonymous form.

\section{Understanding and Building on Anonymity Literature: Dissenting Voice Between Freedom of Speech and Lack of Accountability}

Anonymous communication consists in the communicative situation in which a message source is absent or unspecified to the message receivers, or in some cases hidden behind an alternative, fictitious identity through a pseudonym (Anonymous, 1998; Scott, 2004). Scott, Rains, and Haseki trace the very long tradition of anonymous communication "from anonymous Puritan attacks against the Anglican Church in the 1500 s to a wide range of unsigned paintings and writings through much of the recorded history, and from the pseudonymously published Federalist Papers over two centuries ago to the millions of unidentified online messages today" (2011: 299). Clearly, anonymity has grown as a central variable of interest due to contemporary communication technologies, and become a problematic issue as witnessed by the numerous cases of employee dismissals and corporate scandals linked to online disclosure and information leaks (Anonymous, 1998; Lipinski, 2002; Scott et al., 2011; Shoss, Maurer, \& Rupprecht, 2013).

Anonymity is a basic right of free speech which protects unpopular views from retaliation in most democracies, like in the US where this interpretation is historically upheld in courts (Scott, 2004). Nevertheless, its general merits and pitfalls have been widely debated in literature. On the one hand, anonymous communication is praised for reducing the risks of persecution and retaliation (Bishop \& Levine, 1999; Scott \& Rains, 2005); focusing attention on the message content rather than its source (Marx, 2001); encouraging the sharing of sensitive and problematic issues without fear of embarrassment or consequences for one's reputation; and facilitating participation, especially among marginalised groups and, in general, those who might feel uncomfortable interacting without anonymity (Scott et al., 2011). On the other hand, anonymous communication is also weighed down by significant drawbacks related, in particular, to the loss of input recognition and efficacy in affecting decision-making outcomes, and the issues of disruptive conversational behaviour and accountability because dissenters are not confronted with the need to justify or defend their comments (Anonymous, 1998; Klaas et al., 2012; Scott, 2004).

When it comes to the specific realm of employee dissent, existing studies have largely overlooked "discursive anonymity" (Scott et al., 2011). The need to delve deeper into employee anonymous disclosure is relevant in all those cases in which dissenters do not have strong relations with others in the workplace and 
feel uncomfortable overtly sharing criticism about the organisation, management, and co-workers (Bishop \& Levine, 1999; Scott \& Rains, 2005; Scott et al., 2011).

This picture is growing more and more complex, considering that much employee dissent is progressively migrating to online outlets (Balnave et al., 2014; Bishop \& Levine, 1999). Employees displace dissent online because they feel they have more control over the discussion and involve a larger and more supportive audience (Gossett \& Kilker, 2006; Kassing, 2011). Increasingly, they choose anonymous, de-identified outlets after open online disclosure has exposed some employees to retribution (Shoss et al., 2013; Stohl et al., 2017; Valentine, Fleischman, Sprague, \& Godkin, 2010). Still, the affordances of the digital environment remain an underdeveloped area in dissent research (Klaas et al., 2012). Although we acknowledge that anonymous (and pseudonymous) online communication might be more or less traceable (Kling, Lee, Teich, \& Frankel, 1999), for example through logs, here we focus on anonymity as perceived by the communicators involved, where this perception affects usage and communicative behaviour (Christopherson, 2007; Scott, 2004). We build on this, concentrating on the digital sphere as an alternative outlet for employee displaced dissent in anonymous form.

\section{Understanding and Building on Online Communication Literature: New Possibilities for Expressing and Organising Dissenting Voice}

Today's organisations and society at large are embedded in multiple, fluid social and communicative networks (Castelló et al., 2013). In particular, the contemporary digital environment makes up a new communicative and textual space (Lillqvist \& Louhiala-Salminen, 2014) thanks to high accessibility, speed, inexpensiveness, multimodality, visibility, editability, and lastingness of messages, and ability to communicate horizontally across a large and varied audience (Castells, 2007; Whelan et al., 2013).

Literature on online communication highlights that the digital space produces a "dynamization of communication" (Castelló et al., 2013) facilitating more visible, decentralised and democratic participation of various actors (Whelan et al., 2013) and transformation of individual voices into collective decisions through the mechanisms of aggregation (Surowiecki, 2004). The growing body of studies on polyphony designates the digital space as the public forum for embracing dissensual voice and realising productive conflict with a view to innovation, ethically responsible organisation and societal renovation (Guthey \& Morsing, 2014; Trittin \& Schoeneborn, 2015).

In particular, anonymity in online contexts facilitates even more disclosure and participation and especially on controversial topics (Scott et al., 2011), serves as an equaliser (Christopherson, 2007), and attenuates fear of isolation and tendency to conform to others (Alonzo \& Aiken, 2004; Ho \& McLeod, 2008). Perhaps counterintuitively, based on the principle of similarity found in attribution theory (Kelley \& Michela, 1980), online anonymous communication is also considered credible, because the receiver may interpret the anonymity of a message as an effect of the source's fear, which in turn is considered an indication of the importance of content (Rains, 2007). Callison (2001) even found that anonymous generic sources are rated 
as more credible than organisational sources. Lankes (2008) adds that credibility of anonymous sources in online outlets is strengthened by "reliability," where users seek commonalities among multiple information sources and evaluate coherence over time.

On the other hand, scholars point out that the plurality of voices allowed by the online environment may also increase the potential polarisation of reality constructions and radical views within specific communities (Castelló et al., 2013; Christopherson, 2007). Besides, some actors may be more interested in "trolling" or provoking (Whelan et al., 2013), putting on the agenda marginal issues or unsubstantiated arguments. Specific research on anonymous online outlets stresses that anonymity and reduced sense of accountability may encourage false or distorted assertions (Scott et al., 2011) and anti-social behaviours like flaming (Alonzo \& Aikens, 2014; Scott, 2004).

The contemporary digital environment increasingly exposes organisations and becomes a leverage for confronting irresponsible business practices (Stohl et al., 2017). Whelan, Moon, and Grant (2013) talk about the emergence of "public arenas of citizenship" where individual citizens are empowered in actively creating and shaping organisational and public good issues. At the same time, scholars also point to new opportunities for organisations of creating their own "corporate arenas of citizenship" (Whelan et al., 2013) and even "dissent enabling public spheres" (Whelan, 2013), which are concerned with actively acknowledging and confronting corporate-civil society discordance.

Despite evidence indicating a significant growth in the phenomenon of employee dissent in online contexts (Balnave et al., 2014; Shoss et al., 2013; Stohl et al., 2017), surprisingly this remains an underdeveloped research area. Most of the existing research on anonymous online dissent has focused on customers (e.g. Hennig-Thurau, Gwinner, Walsh, \& Gremler, 2004). To our knowledge, only a few scholars have investigated the phenomenon of EAOD. Their research has touched upon its strengths and weaknesses, for example public solidarity and visibility versus distortion and lack of a disciplined approach to negotiation (Real \& Putnam, 2005; Taras \& Gesser, 2003); goals, namely to damage the organisation, or to change its practices and/or society at large (Krishna \& Kim, 2015; Shoss et al., 2013); and effects in terms of impact on perceptions and reactions of "outsiders," such as former employees, journalists, and customers (Kulik, Pepper, Shapiro, \& Cregan, 2012), and on the organisation expected to take into consideration employee dissensual voice (Gossett \& Kilker, 2006). However, existing literature fails to gather together these preliminary analyses, which our present examination intends to do with a view to understanding "how web-based technologies are shaping the development of employee voice, and the challenges, hurdles and solutions that are emerging along the way" (Balnave et al., 2014: 452).

\section{ROOTING OUT THE INTRICACIES OF THE COMMUNICATIVE PROCESS OF EAOD}

In this section, we attempt to reorganise the insights from the reviewed literature and scarce existing research on EAOD to delineate a multi-actor, dialectical model of this phenomenon, while also uncovering the complexities and challenges it brings about. 
First of all, it is necessary to specify that we conceptualise EAOD as a communicative and interactional process. Dissent in itself is a communicative act (Kassing, 2011) since it does not stop with feeling apart from one's organisation, but requires expressing why one has developed an oppositional stance. Besides, we appropriate Garner's (2013) interpretation of dissent as a process, rather than an isolated, onetime event, in which interaction is centrally situated and the stories and discourses of others add to the initial dissent conversation, co-constructing its development and outcomes. Whereas Garner in his critique of dissenter-centric research has explored the process of co-constructing dissent among dissenters, managers, and co-workers within organisations, here we build on this to explore EAOD as a multi-actor, dialectical process that crosses organisational boundaries and extends interaction from dissenting employees and their organisations to other key actors, namely administrators of online outlets hosting employee dissent and the audiences reading and participating in such online discussions.

Moreover, we build on Garner's proposal to consider the multiple interests and cognitive processes that underlie the dissent process, and point out actor-related tensions involving different decision-making paths and communicative tenets (Stohl et al., 2017). "Tension" refers "to the clash of ideas or principles or actions and to the discomfort that may arise as a result" (Stohl \& Cheney, 2001: 353-354). Such actor-related tensions and subsequent communicative actions flow into the process of EAOD, at the same time shaping and being shaped in the interaction with others.

\section{EAOD as a Multi-actor, Dialectical Process}

In the following, we go through the communicative process of EAOD by focusing on its four key actors and discussing actor-related tensions, communicative behaviours, and outcomes.

\section{Dissenting Employees}

We look at employees as those who initiate the communicative process of EAOD when they decide to express their disagreement outside the organisation and opt for anonymous dissent via online public outlets.

Employees may experience a first tension between being loyal to their organisation and colleagues, and disclosing dissent to voice their concerns and conscience (Shahinpoor \& Matt, 2006). Organisational, relational, and individual factors determine employees' decision to share dissent outside the workplace. In particular, evidence shows that employees are more likely to displace dissent when they believe that they will be viewed as destructive by management and co-workers (Kassing, 1997); are younger non-management staff with less work experience (Kassing \& DiCioccio, 2004); have low quality relationships with others in the organisation (Kassing, 2011; Scott et al., 2011); and lack a sense of personal influence and satisfaction (Kassing, 1998). Among alternative outlets, the online environment, in particular anonymous spaces, appeal to dissenting employees due to public visibility and solidarity, lower risk of retaliation, the possibility to express minority opinions or controversial topics not shareable with supervisors or co-workers (e.g. intention 
to leave), and the emphasis accorded to one's social identity as a member of the organisation rather than individual identity (Gossett \& Kilker, 2006; Kulik et al., 2012; Rains \& Scott, 2007; Shoss et al., 2013).

Another tension can be identified in terms of the goal guiding the communicative behaviour. Employees may adopt a constructive and prosocial motive, which we further differentiate between soliciting change in the organisation and/or society at large, and a destructive and revenge-driven motive resulting from the desire to hit the organisation. The latter is more likely to occur when anonymous online dissent is used to release negative emotions, where employees are "seeking to restore justice by using voice as revenge. Harming the reputation and image of the employer in the community may be seen as a way to impose costs on the employer and achieve some level of retributive justice" (Klaas et al., 2012: 337). However, we also argue that dissent is not always singularly focused, and in reality, constructive and destructive elements may be more or less prevalent and flow into a mixed motive (Klaas et al., 2012). For example, the dissenter may be motivated by the desire to stimulate organisational and/or societal reflections, while also seeking retribution by imposing costs on the organisation.

Finally, a tension may be identified when employees decide upon framing the message they want to share (Garner, 2009), pursuing honest or fabricated communication. As seen, anonymous voice is characterised by an accountability issue with regard to what is stated. Employees who pursue a more destructive motive may draw on misrepresentation or exaggeration with the intention to impress audiences, advocate their reasons against their employer, or embarrass organisational officials while also consuming their time and energy in conducting investigations (Klaas et al., 2012). Sometimes even prosocial motives risk being invalidated by insincere statements and distortions (Scott et al., 2011).

In sum, employees who externalise dissent via online public outlets might experience tensions in terms of loyalty toward the organisation versus voicing their concerns for a sense of justice and individual safety; soliciting change versus seeking revenge; and honest versus fabricated disclosure.

\section{Online Outlet Administrators}

The administrators of online outlets are those hosting and mediating employee dissent in public fora, such as counter-institutional and review websites and confessions pages, and thus those enabling public arenas of citizenship (Whelan et al., 2013), and counter-hegemonic discourse (Salter, 2013).

A first tension in which the administrators of online outlets may find themselves involved is between preserving online anonymity for safe disclosure and privacy rights, and integrating identity checks to ensure accountable and transparent disclosure. As already pointed out, the lack of accountability linked to the anonymous status of the dissenters can lead to misrepresentation and even promotion of false assertions (Lipinski, 2002; Scott, 2004) on the part of employees in the first place, but also from online audiences, competitors, and even organisations themselves when engaging in dialogue on these platforms in order to advocate their respective positions. 
On the other hand, evidence shows that identification hinders participation (Rosenberry, 2011).

Another tension experienced concerns the quality of comments and freedom of expression. As shown by research on online anonymous commentaries (Hlavach \& Freivogel, 2011; Rosenberry, 2011; Strandberg, 2008), administrators face a tension between keeping participation high through freer and livelier dialogue, and moderating and controlling dialogue to stay true to ethical principles related to minimising harm and being themselves accountable. Online platforms, in fact, base their success on the number of active users and comments, and their spontaneity. Nevertheless, administrators are challenged by the difficulty of monitoring statements in real time, managing disputes, and filtering uncivil anonymous commentary (Rosenberry, 2011) which renders online dialogue ineffective.

A last tension regards the decision about whether to offer companies the possibility to intervene and directly respond to online criticism, or to give priority to employee dissensual voice. Studies point out that complaining is actually encouraged on these sites (Shoss et al., 2013), where providing organisations with the possibility for counter-communication may undermine the profile of the online outlet as a counterinstitutional space for minority voices.

All these considerations concerning the administrators of online outlets point out key tensions between protection of safety, privacy, and anonymity versus accountability checks; freedom of expression versus moderation; and visibility of employee dissensual voice versus inclusion of the counter-communication of the organisation, for a more informed and nuanced discussion.

\section{Online Audiences}

Online audiences encompass "outsiders" with varying degrees of organisational affiliation (Kulik et al., 2012), such as customers, former employees, employees of competitors, journalists, and general public, who are brought together by online outlets. We see the role of organisational outsiders as particularly relevant in EAOD because of their participation in the dialectical exchanges and the additional pressure they might eventually put on organisations. Nowadays, a great deal of the information people have about an organisation is formed and incorporated through the collective experience and accounts of other people (Skarlicki \& Kulik, 2005), and more and more through electronic word-of-mouth (Hennig-Thurau et al., 2004), which has proven to be powerful in forcing companies to change their behaviours (Van Laer \& Van Aelst, 2010).

Similar to what has been discussed in relation to employees, audiences with a former or current relationship to the organisation in question (e.g., job applicants, former employees, journalists, and customers) might immediately experience a tension between loyalty to the organisation and criticism against its behaviour.

Moreover, online audiences face the challenge of weighing the credibility and accountability of the sources, experiencing themselves the tension between honest versus fabricated interventions. First, as explicated by the theory of social contagion and contagious justice, individuals may fail to call into question message righteousness and dissenter motivation (Rains, 2007), and uncritically imitate or even exaggerate 
the original thoughts (Barsade \& Gibson, 1998) to support dissenters in their pursuit of justice (Degoey, 2000). Second, there might be cases in which some actors may purposefully misrepresent the original views and intentions of employees, for example, to raise the visibility of their own agendas, including competitors aiming to damage the targeted organisation (Krishna \& Kim, 2015).

On the whole, these considerations highlight the complexity brought about by the decisions and communicative behaviours of online audiences, where again we can trace major tensions in terms of loyalty versus criticism toward the organisation, indulgent acceptance versus critical questioning, and honest versus fabricated interventions.

Targeted Managers and Organisations

Finally, organisations play a key role in the communicative process of EAOD, in particular in relation to its initiation and possible outcomes.

First, a main tension stems from tolerating employee dissent as opposed to protecting the organisation, its functioning, and reputation by controlling the free expression of dissent, especially outside the organisation. Some organisations have, in fact, introduced communication and social media guidelines in the effort to prevent undesired employee communicative behaviours external to the organisation, providing codes of conduct for employee access, information dissemination, and preferred tone of voice (Stohl et al., 2017). This, while protecting the organisation and its property rights in the business, also limits the principle of freedom of expression in that organisations extend their control over the personal lives of employees (Balnave et al., 2014) and often take disciplinary action toward employees being disrespectful of such guidelines (Valentine et al., 2010).

Another tension inheres in the decision of whether to react to EAOD or ignore it. Here, we point out three main possible directions: organisations may immediately cast EAOD as destructive, disloyal, and irresponsible employee commentary (Stohl \& Cheney, 2001; Stohl et al., 2017) and ignore it; they may opt for engaging dialogically with dissenters and other online audiences for counter-communication aimed to clarify their position on the subject (Scott, 2004); and/or they may opt for proactively addressing EAOD by changing internal policies and practices accordingly, which we label as "internalisation" of dissent.

The dismissal of EAOD might depend on organisational and cultural factors, such as absence of issue monitoring tools and adverse climate for voice, or the actual difficulty of processing and managing too much dissensual voice (Kassing, 2011). Nonetheless, ignoring EAOD is a visible (non-)action in the eyes of dissenters and online audiences and might entail some risks. First, EAOD has the potential to generate "paracrises" (Coombs \& Holladay, 2012) by engaging other stakeholders, which threatens the legitimacy and credibility of the organisation and sometimes even causes economic damage (Scott, 2004). This occurs because insiders have great influence on outsiders' perceptions and opinions and, in turn, on public opinion (Kulik et al., 2012). Among such audiences, former employees from the same organisation have been shown to have a great effect on organisational reputation when they participate in dissent over time, even though their formal affiliation to 
the organisation has ended (Gossett \& Kilker, 2006; Kulik et al., 2012). In addition, considering that some people perceive anonymous sources to be as credible and influential as identified ones (Rains, 2007), the quality of relationship between the organisation and its current employees, even if not actively participating in online dissent, might be put at stake.

On the opposite side, organisations may proactively internalise EAOD and change existing corporate behaviours in terms, for example, of a revision of internal voice systems or of those specific practices that triggered dissent in the first place (Kassing \& Armstrong, 2002). Thus, EAOD can turn out to be a form of upward dissent targeted at managers, and lateral dissent targeted at colleagues, coming from outside the organisation. Empirical evidence actually suggests that some employees purposefully complain online because they assume that their management reads and monitors such online outlets (Gossett \& Kilker, 2006). In addition, given that EAOD is being discursively reshaped through other actors' voices, it allows the representation of societal voices and discourses in organisational settings; Trittin and Schoeneborn (2015) label this "discursive diversity," which leads to greater awareness and corporate social responsibility (Balnave et al., 2014).

Finally, when organisations decide to use online public outlets "to post an organisation's perspective or to provide an alternative viewpoint on the subject" (Scott, 2004: 138), a last tension relates to whether to adopt an approach based on transparency or on "simulated openness" (Christensen et al., 2008: 129), similar to what has been discussed in regard to other actors.

To summarise, organisations are challenged in making a choice between tolerating versus controlling employee dissent; ignoring versus answering back and/or internalising EAOD; and - in the case of counter-communication-adopting a response strategy based on transparency versus simulated openness. Figure 1 delineates the multi-actor, dialectical process of EAOD.

\section{Toward a Model for Responsible EAOD}

Our prior analysis reveals the complexity of the communicative process of EAOD, comprised of the plurality of actors, actor-related tensions, communicative behaviours, and possible outcomes involved. Such reflections highlight the pervasiveness of multiple stances and divergent communicative principles and actions that flow into and shape this process. We particularly stress that individual efforts to solve the tensions experienced, and to pursue actor-centred aims, may encounter limits or generate unethical consequences if single interests and arguments are not brought out and confronted in joint public discourse. This highlights the potential value of dissent inherent in its open expression and co-construction in public discourse, but also the potential challenges centred around how various actors can express their different voices and engage in meaningful dialogue in a responsible way in order to reap the benefits of dissent (Dawkins, 2015; Kassing, 2011; Shahinpoor \& Matt, 2006; Whelan, 2013), such as correction of unfair organisational practices, while limiting self-centred, unaccountable, and opportunistic behaviours (Castelló et al., 2013; Krishna \& Kim, 2015), which actually dilute voice and reduce negotiation of viewpoints and solutions between opposed positions. 


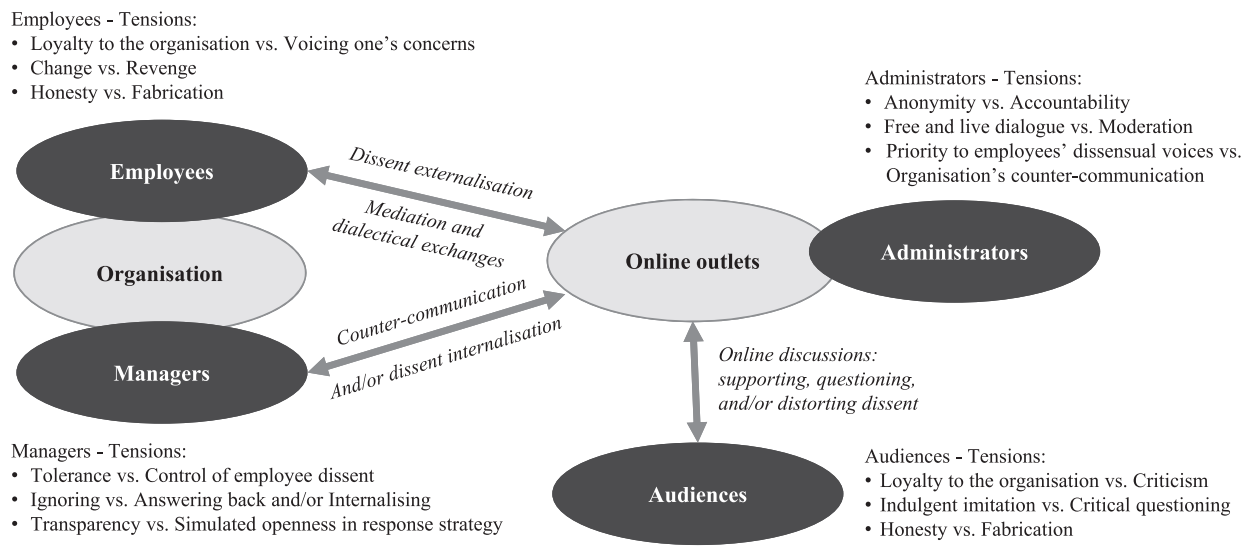

Figure 1: The Multi-Actor, Dialectical Process of EAOD

The question of co-responsibility (Lozano, 2005) and mutual influence across actors in contemporary network society is central in business ethics literature. Young (2006) emphasises that actors are connected to an issue indirectly by virtue of social relations, and engage in public communication for the sake of organising relationships and actions whose intended outcome is the solution of the issue and, possibly, a revision of the system that produces and perpetuates it. In the same vein, we emphasise that a responsible communicative process requires embedding single actors in a wider network of interdependencies and openly negotiating the different voices in meaningful communication in order to reach a common understanding.

While EAOD helps realise the communicative conditions for social connection and public discussion, we are also aware of the challenges involved in this practice. More specifically, we can derive from the multi-actor, dialectical model of EAOD three central open questions related to responsibility and public discourse: a) how is it possible to make up for the lack of accountability linked to anonymous communication and for the opportunism interacting actors may adopt? b) How can online spaces and dialogue facilitate equal participation and influence the resolution of actor-related tensions and consequent communicative behaviours? c) Why should organisations participate in online dialogue, in an accountable way, and eventually internalise dissent through proactive change? In the following, we address such open questions by appropriating a Habermasian lens.

\section{APPROPRIATING A HABERMASIAN LENS: FROM MARGINAL DISSENSUAL VOICE TO PLURAL DELIBERATIVE DISCOURSE}

Stahl (2005) emphasises that responsibility across actors is best achieved through participatory deliberative processes, which in our particular instance take shape through the affordances and constraints of online anonymous communication. In the following, we appropriate Habermas's discourse ethics and communicative action theory $(1992,1993,1994,2001 \mathrm{a}, 2001 \mathrm{~b})$ to address the above stated open questions and eventually show how the multi-actor, dialectical dissent process can be actualised in a responsible way through deliberative discourse. 
It is first of all necessary to sketch out the main tenets of Habermas's discourse ethics and communicative action theory. This ethical and discursive lens focuses "on the process of reaching valid, moral norms through participating in fair dialogue" (Goodman \& Arenas, 2015: 168) where a plurality of actors can express their voice under undistorted conditions (Beschorner, 2006; Habermas, 1992, 1994, 2001a). This long-standing ethical theory is increasingly used in business ethics and CSR literature to problematise business practices (Beschorner, 2006) and explore issues such as social shareholder engagement (Goodman \& Arenas, 2015), corporate legitimacy (Palazzo \& Scherer, 2006), political CSR (Scherer \& Palazzo, 2007; Whelan, 2012), and business-NGO interaction (Baur \& Arenas, 2014).

Habermas's theory centres around the idea of "public sphere"- a space in which civil actors deliberate problems and common good independently from state and economy interference-and looks at communicative actions in linguistically mediated interactions in opposition to strategic actions (1992, 2001a). In "strategic action," actors are not so much interested in mutual understanding as in pursuing egocentric and utilitarian aims, which may lead to distorted and pseudoconsensual communication. In "communicative action," actors coordinate the pursuit of their goals by freely agreeing that the goals are merit-worthy or reasonable. More specifically, Habermas (2001a) provides four pragmatic presuppositions of communicative action: a common objective world as a shared referential system; the accountability of subjects, regarded as the rationality that participating actors mutually attribute to one another, at least provisionally; the unconditional validity of truth and moral rightness which participants claim for their statements via speech acts; and finally, the implicit orientation toward discursive justification, a process that forces participants to decentre their interpretive perspectives and validate their claims.

Only through practical discourse can participants engage in an exchange of voices and reach mutual understanding, whereas such a negotiation and agreement cannot be realised in monological forms of individual deliberation (Habermas, 1992). When advancing the possibility for intersubjective understanding in communication, Habermas talks about "the unity of reason in the diversity of its voices" which can be realised as participants "open up both the possibility for ego to adopt the perspective of alter and vice versa" (1994: 138), and thereby "reach mutual understanding across the boundaries of diverging lifeworlds" (2001a: 21).

Goodman and Arenas (2015) summarise the key rules of Habermasian discourse as: argumentation, the dialogical and interactional process focused on transforming diverse perspectives rather than simply aggregating them; plural participation, where "every subject with the competence to speak and act is allowed to take part in a discourse" (Habermas, 1992: 89); non-coercion, which emphasises the right of all actors to participate, express themselves, and question others without any form of pressure; and transparency, which requires participants' orientation toward truthful statements but is, in any case, regulated by the processes of deliberation and justification which can at least lead to decisions about the rational acceptability of propositions (Habermas, 2001a).

By use of this lens, in the following we examine and disentangle the three open questions centred around: a) lack of accountability and potential opportunism; 
b) equal participation and resolution of actor-related tensions; and c) organisational participation and internalisation of dissent.

\section{How is it Possible to Make Up for the Lack of Accountability Linked to Anonymous Communication and for the Opportunism Interacting Actors May Adopt?}

This first open question regards how to take on the central issues of accountability and strategic action in EAOD, issues feared by Habermas himself as increasingly invading the public sphere (Dahlberg, 2005). If we look more closely at the Habermasian communicative principles of argumentation and transparency (Goodman \& Arenas, 2015), all actors must be able to freely express their voice in a context open to criticism and questioning by others, including dissenters, online audiences, and organisations willing to engage in such online dialogue.

Online public anonymous outlets extend the public sphere and its capacity to allow for the visible expression of dissent messages, while these are concurrently being openly questioned by other actors who can object to them and test their rational justifiability. Given that speech acts inherently involve claims that are in need of justification, the central problem of actors' accountability in the EAOD communicative process is overcome by the intersubjective validity of claims resulting from the processes of plural deliberation and falsification.

We add to this the possibility in online contexts of achieving reliability (Lankes, 2008) through different sources and experiences (e.g., of former employees) which help test claims and revise participants' pre-understanding. This is consistent with Habermas (2001a: 14) explaining that "truth claims can be called into question in any given context only if the corresponding propositions that are 'true' in one context cannot lose that property in another." This also addresses the need for contexts offering "conditions of communication that prevent corruption by power differences and strategic motivations" (Dawkins, 2015: 6) in deliberative practices. In deliberative communication, "discourse quality derives from the analysis of arguments, not actors" (Scherer \& Palazzo, 2007: 1109), their identity, and motives. So it is only in communicative action that it becomes "clear who is frustrating the pragmatic presupposition of accountability and is not even "in the game"" (Habermas, 2001a: 26), and that manipulation, coercion, and domination can be exposed (Dahlberg, 2005).

\section{How Can Online Spaces and Dialogue Facilitate Equal Participation and Influence the Resolution of Actor-Related Tensions and Consequent Communicative Behaviours?}

In addressing this second open question, the Habermasian communicative principles of plural participation and non-coercion (Goodman \& Arenas, 2015) come into play. Anonymous online public outlets sustain the equal participation of marginalised voices (Christopherson, 2007; Scott et al., 2011) in a way that these remain unaffected by fear of retaliation, and undistorted by indirect representation (Habermas, 1992). The public sphere norm even makes room for aesthetic-affective modes of communication (Dahlberg, 2005), typically found in disruptive or emotional dissenting acts (Grant, 2013; Klaas et al., 2012), which can be beneficial in drawing greater attention to marginalised concerns, supporting the thematisation of claims, 
and calling into question dominant positions. Further, through the mechanisms of aggregation, such minority voices can gain strength and eventually be transformed into collective decisions (Dahlberg, 2005; Surowiecki, 2004) beyond physical and national boundaries (Van Laer \& Van Aelst, 2010; Young, 2006).

Here, we outline the key role played by the administrators of online outlets that host employee dissent and subsequent public deliberation developing around it. First of all, we stress the overall value of these dedicated online arenas, consisting in their enhanced capacity to collect otherwise isolated dissent events and realise the fundamental performative presupposition of communicative action: "Neither pro nor con arguments can have any weight unless there are communicative situations that can bring out the unforced force of the better argument" (Habermas, 2001a: 14) and, we add, bring out the actor-related tensions that would not be easily solved through mere individual monologue (Habermas, 1992). In addition, the role of administrators as mediators contributes to building trust in an online anonymous context (Nissenbaum, 2003) and ensuring a balance between maximisation of inclusion and equality, and minimisation of domination and anti-social behaviours (Alonzo \& Aiken, 2004; Dahlberg, 2005; Scott, 2004; Scott et al., 2011).

However, similar to what we have already discussed in relation to the accountability of interacting actors (dissenters, online audiences, and/or organisations), there might be instances in which also administrators have a bias toward not acting accountably and impartially. This occurs, for example, when they are mostly interested in keeping participation high and do not engage in thorough identity verification, or in giving emphasis to anti-organisation voices as in the case of confessions pages set up by dissatisfied employees themselves. Habermas has addressed these limits of an "ideal speech situation" (Habermas, 1992: 88) often criticised by his detractors (e.g. Dawkins, 2015; Fraser, 1990; Salter, 2013). In some of his most recent works, Habermas acknowledges that in daily communicative situations people might pursue strategic action, and, interestingly, he observes that the process of argumentation is "self-correcting," since in the course of an unsatisfactory discussion "reasons spontaneously arise for an 'overdue' liberalisation of the rules of procedure and discussion, for changing an insufficiently representative circle of participants, for expanding the agenda or improving the information base" (2001a: 35). This selfcorrecting mechanism is clearly facilitated by the affordances of online communication because it offers a more accessible, multisource, and flat playing field for varied and dispersed social actors (Castelló, et al., 2013; Castells, 2007) who are equally free to advance, expand, and call unsatisfactory arguments into question.

\section{Why Should Organisations Participate in Online Dialogue, in an Accountable Way, and Eventually Internalise Dissent Through Proactive Change?}

This last open question concerns why organisations should be willing to participate in online dialogue, following principles of honesty and accountability, and eventually internalise EAOD, adopting corrective actions to address the concerns externalised by the dissenter(s). Research in business ethics (Palazzo \& Scherer, 2006) highlights that the transition from stable industrial society to pluralistic, postindustrial, and postnational society (Habermas, 2001b) is putting corporate legitimacy at stake. 
This changing context requires organisations not to pay exclusive attention to the demands of powerful groups, but to move toward "moral legitimacy" as the essential source of social acceptance and licence to operate. Moral legitimacy is socially constructed in communication by offering and considering reasons to justify the behaviour of an organisation, described by Palazzo and Scherer as "processes of active justification vis-à-vis society through communicative engagement in public deliberation" (2006: 72).

In relation to our discussion of EAOD, it is important to highlight that we are not disregarding the fact that corporate decision making may be based on instrumental reasons such as the prevention or containment of those economic and reputational consequences created by employee disclosure and discussed when dissecting organisation-related tensions. Rather, organisations may opt for actively engaging in public discourse to counteract such negative effects while also reinforcing their legitimacy. Because legitimacy is hardly bought (Suchman, 1995), and merely symbolic activities might even increase public outrage, organisations are "to engage in true dialogue, to convince others of the validity of one's argument but not to persuade or manipulate by means of strategic instrumentalization" (Palazzo \& Scherer, 2006: 81). Castelló, Morsing, and Schultz talk about "communicative legitimacy" where "an organization that is able to appreciate dissent is likely to react to the dissent by diversifying its own reality and become polyphonic, and might be perceived as being legitimate even by those same critical stakeholders and observers who question its behaviors" (2013: 689). Thus, dissent is the necessary condition for the communicative constitution of legitimacy (Castelló, et al., 2013) and the spark for incorporating discursive diversity (Trittin \& Schoeneborn, 2015), possibly leading to the internalisation of dissent.

\section{Drawing the Strands Together: A Deliberative Perspective on EAOD}

The combination of the Habermasian lens with the practical phenomenon of EAOD has provided us with compelling ways to examine and disentangle the three open questions stemming from the multi-actor, dialectical model of EAOD developed in the first part of this article, and thus advance a more reflective and nuanced understanding of how EAOD may be actualised in a responsible way through deliberative discourse.

First, from a deliberative perspective, dissent enters rightfully into the plurality of voices without being necessarily dismissed or subsumed in one dominating rationality, typically that of the organisation (Christensen et al., 2008), and without remaining confined to unfruitful monological processes of individual deliberation (Habermas, 1992) which prevent the resolution of actor-related tensions through reflective distance (Dahlberg, 2005) and transformation of perspectives (Goodman \& Arenas, 2015).

Second, anonymous deliberation allows direct and non-threatened representation (Bishop \& Levine, 1999; Scott \& Rains, 2005), and therefore more democratic participation and visibility of marginalised and powerless voices (Scott et al., 2011). The risks of lack of accountability and of disruptive and manipulative behaviour can be limited in practical discourse by the intersubjective validation and revision 
operated by actors through argumentation. This process is even enhanced in online communicative contexts thanks to cross-source reliability (Lankes, 2008) and self-correction mechanisms (Habermas, 2001a), where anonymous dissenters (and other actors) are inescapably confronted with the need to justify and defend their positions (Anonymous, 1998; Klaas et al., 2012; Scott, 2004).

Finally, EAOD ensures visibility and continuity of conversation over time, involving a larger audience (Gossett \& Kilker, 2006) in a full exchange of ideas on complex issues (Klaas et al., 2012), prevents the possible loss of input (Scott, 2004) from unexpressed and ignored concerns, and eventually transforms isolated voices into a collective stance (Dahlberg, 2005; Surowiecki, 2004), thus creating viable opportunities for these voices to be heard and internalised by organisations. When organisations acknowledge EAOD and participate in public deliberation, dissent is transformed from a dysfunctional condition (Kassing, 2011) into a source of productive disagreement and communicative construction of corporate legitimacy (Castelló et al., 2013; Palazzo \& Scherer, 2006).

Taken all together, a deliberative perspective on EAOD highlights that the externalisation of employee anonymous dissent via online public outlets is a significant, although not uncomplicated, starting point for the expression of employee marginalised voice and actors' mutual recognition, and the communicative and interactional process through which different actors can bring out individual tensions, exchange arguments, co-construct dissent (Garner, 2013), address conflicts, and derive judgements and decisions in a more informed and balanced manner (Habermas, 2001b; Palazzo \& Scherer, 2006). All this supports our argument for a possible and fruitful responsible communicative process actualised through public deliberation and balancing across actors in practical discourse, releasing the value inherent in employee online dissent while counteracting its possible downsides.

We add that the value of publicly expressing and deliberating dissensual voice lies in its overall capacity to revitalise corporate-society dialogue and reflection, also in those instances in which compromise among actors and/or internalisation of dissent by organisations cannot be fully reached. As Scherer and Palazzo put it, "it is not necessary to achieve an ideal speech situation in order to have the described positive effects of deliberation" (2007: 1107). Their reinterpretation of Habermasian thinking, which they call Habermas 2 , "suggests small steps of constant improvement and transformation .... Additionally ... it is acknowledged that it might be even more important to find a rational basis for a (more likely) disagreement" (2007: 1107), so that actors and organisations are not entrapped in unlimited democratic discourses but still benefit from the richness that the diversity of positions brings to the process. Whelan (2013) adds that public spheres which enable dissent and corporate-society confrontation contribute to the general social good because they help form a broader and stronger awareness, and realise that social harmony often derives from acknowledging a reality of social difference.

To conclude, online public deliberation initiated by employee dissent could be considered a case of noninstitutionalised and decentred interaction, open to unregulated and informal contact between corporations and society (Baur \& Arenas, 2014). Contrary to more conventional and institutionalised contexts which tend to exclude 
certain groups from deliberative dialogue (Dahlberg, 2005), we advance EAOD as an actualisation of such an extended deliberative perspective, and conceive of it as an open-ended, polyphonic dialectical process that provides the basis for clearing up new or not yet well-defined issues (Baur \& Arena, 2014) and can potentially function as a catalyst for acknowledging and internalising dissent on the part of organisations.

\section{Practical implications}

A deliberative perspective on EAOD can offer a point of reference for developing sensitivity to this growing phenomenon and for inspiring practical interventions. In the following, we extract three key implications that are relevant to practice.

First, the challenges related to opportunism, anti-social behaviours and lack of accountability call for improving online media literacy. According to UNESCO (2017), media and information literacy can provide twenty-first century citizens with analytical and judicious competencies "at the core of freedom of expression and information-since it empowers citizens to understand the functions of media and other information providers, to critically evaluate their content, and to make informed decisions as users and producers of information and media content." Online media literacy has the potential to fulfil plural argumentation and co-construction of dissent according to a deliberative perspective, as it concerns collective representation of knowledge and values, diffusion of interpretative abilities, and democratisation through critical participation of ordinary people (Livingstone, 2004) in their role as disagreeing employees or audiences. The development of online media literacy also requires the improvement of technological infrastructures and information checking possibilities, and in particular, the connection to multiple online and offline information sources.

Second, the challenges linked to equal participation and resolution of actor-related tensions through social connection and public deliberation require, from a practical point of view, nurturing trust in online anonymous outlets and enabling transparent public arenas of citizenship (Whelan et al., 2013). Following Habermasian principles, administrators of online outlets in particular can create plural anonymous environments that are both successful and effective if they implement some degree of checks and balances, for example: accepting comments based on confidentiality (Hlavach \& Freivogel, 2011), formulating explicit communication rules, facilitating a more disciplined approach to dialogue (Taras \& Gesser, 2003), and consenting a large network of users, including organisations, to respond to and participate in the conversation (Gossett \& Kilker, 2006), thus expanding the agenda to the positions of other actors. Particularly relevant, nowadays, is improvement of the information retrieval and fact-checking regarding these online outlets to contrast the emerging issues of "fake news." For example, Facebook has recently implemented a series of tests and fact-checking in collaboration with news organisations (Isaac, 2016).

Finally, for companies, the challenges linked to organisational communicative engagement, legitimacy building, and internalisation of meaningful dissent highlight the opportunity to create, externally, their own online "corporate arenas of citizenship" (Whelan et al., 2013) which actively recognise and enable public spheres 
of dissent (Whelan, 2013). The implementation and dialogical use of such "owned" spaces would help legitimise organisations as major players in public deliberation, and partly overcome the gatekeeping function of other online outlets (Castelló et al., 2013). Internally, organisations are encouraged not only to develop tools and competencies for monitoring online environments and addressing EAOD at the earliest stage possible, but also to develop their culture toward truly valuing dissent and overcoming the paradox of homogeneity (Stohl \& Cheney, 2001). In this way, potentially useful input that would otherwise be lost (Scott, 2004) could be revealed, and external disclosure prevented through, for example, social intranet spaces (Cardon, 2016) and anonymous apps (Trieu, 2016) for internal use.

\section{CONCLUSION AND RESEARCH AGENDA}

Our work aimed to offer a deeper understanding of employee dissent externalised via anonymous online public outlets. In doing this, we highlighted its value but also acknowledged the complexities and challenges involved in this highly contemporary and controversial communicative practice.

Our article contributes to knowledge within business ethics in two main ways. First, we brought together studies on employee dissent, anonymity, and online disclosure to build a multi-actor, dialectical model of the communicative process of EAOD. In conceiving of EAOD as a communicative and interactional process among multiple actors, we scrutinised the plurality of actors, actor-related tensions, communicative behaviours, and outcomes, which is largely overlooked in literature. Based on this, we identified open questions regarding how actors can engage in this process in a responsible way. Second, to address such challenges, we appropriated a Habermasian ethical and discursive lens to show how this communicative and interactional process can release the value inherent in dissensual, anonymous, online voice through public deliberation and balancing across actors in practical discourse. A deliberative perspective allowed us to argue that the tensions faced by the involved actors could be solved, or at least brought out and confronted in public deliberation, and that the key principles of deliberative discourse applied to online environments could counteract drawbacks of anonymous communication and exemplify a contemporary case of noninstitutionalised and decentred interaction. Based on this, we also offered implications relevant to practice. Our reflections advance the consideration of Habermas's discourse ethics and communicative action theory in business ethics literature (Baur \& Arenas, 2014; Beschorner, 2006; Goodman \& Arenas, 2015; Palazzo \& Scherer, 2006; Scherer \& Palazzo, 2007; Whelan, 2012), in particular, demonstrating its heuristic power when applied to a new and largely unexplored territory: the growing phenomenon of EAOD.

On the whole, although this work is just the beginning of our attempt to disentangle the intricacies of EAOD, our discussion of a deliberative perspective on EAOD lays a more comprehensive, reflective, and ethical foundation for the value and challenges of dissensual voice. As such, our present work has worth also in offering germane reflections to guide future research aiming both to strengthen the framework so far developed and to extend its scope. 
Concerning dissenting employees, future research may further clarify what considerations they go through in choosing online outlets for their venting or in creating a confessions page themselves; what conditions established by the online outlet or technology encourage or discourage their disclosure (e.g. the possibility for the organisation to respond); whether and how they are influenced by audiences' reactions (Marwick \& Boyd, 2011) and/or form coalitions with them; and whether and when online disclosure leads to the exacerbation or softening of disagreement and conflict in relation to the targeted managers and organisation.

When it comes to online outlet administrators organising actual contexts of interaction and deliberation, researchers may benefit from further analysing the range of online outlets hosting employee disclosure, comparing for example counterinstitutional spaces created by employees with third-party review websites; the range of technologies for anonymous online disclosure (e.g., asynchronous/synchronous, anonymising portals) and policies for identity protection, as well as for mediation of conversational dynamics; and the increasing influence of emerging organised movements, such as the Electronic Frontier Foundation and the Global Network Initiative (Whelan, 2013), demanding that administrators and ICT companies such as Facebook support, rather than undermine, human rights.

Related to online audiences, future research could give additional attention to actors' communicative behaviours that challenge or reduce the plurality of voices, such as filtering mechanisms of agenda building and polarisation (Castelló et al., 2013), which are overlooked by current research mostly praising the advantages of digital media. In this regard, future research could also address the role of collective civil actors, such as NGOs, whose influence on organisations is now growing in a context of decentralisation of state authority (Palazzo \& Scherer, 2006). Scholarly interest may be directed toward those specific independent organisations committed to protect freedom of expression and privacy in online environments on a global level, calling out governments and corporations and often challenging unfair efforts to limit online voice or gain access to information and identities of individual citizens stored by online outlets and ICT companies (Whelan et al., 2013).

From the standpoint of the targeted organisation, we need additional insight into strategies and practices of issue monitoring and engagement in digital spaces. For example, this entails considering how discursive openness is pursued by organisations in acceptance of reducing control (Castelló, Etter, \& Nielsen, 2016) over alternative constructions regarding vision, values, and behaviours (Castelló et al., 2013), and also the conditions that make this impractical or dangerous for the organisation. Organisations may, in fact, find themselves in the dysfunctional situation of managing excessive or unfounded dissent (Kassing, 2011) and the impossibility of pursuing unlimited deliberation processes (Scherer \& Palazzo, 2007). Related to internalising EAOD from a co-construction perspective (Garner, 2013), one might also look at co-workers, rather than managers only, and their role in soliciting or hindering the internalisation of dissent externally expressed by colleagues. Literature in business ethics (Dempsey, 2015) has recently started discussing how moral responsibility is generated and distributed in a corporate 
culture, pointing out how all members acquire a degree of individual moral responsibility for organisational outcomes and the actions of others participating in that culture.

Finally, in carrying out future studies, attention could be paid to the legal and cultural factors affecting dissent conceptualisation and practice. Whereas research in legal journals limits its focus on employee online conduct to the perspective of legal rights and obligations in employment law cases (Balnave et al., 2014), we suggest future research to look at the interplay between regulators and administrators of online outlets, ICT companies, anonymous proxy providers, and independent organisations to enhance the ability to discern relative responsibilities in handling rights of privacy, freedom of speech, private safety, and public security, and the relationship between institutionalised and noninstitutionalised settings. Concerning cultural factors, in nations like the US, the free-speech doctrine ensures that speech occurs freely in public without disqualifying employees from protection, but this might not be the case in other countries (Balnave et al., 2014). Cultures seem to differ also in their orientation toward dissent due to individualism and power distance dimensions (Klaas et al., 2012), and ideas about workplace democracy, participation, and freedom of speech (Kassing, 2011). Such conditions and potential biases could solicit reflections on the micro and macro conditions that frame employee dissent as more or less ethical.

\section{ACKNOWLEDGEMENTS}

We are grateful to associate editor Andreas Georg Scherer and three anonymous reviewers for their time and insightful suggestions.

\section{REFERENCES}

Alonzo, M., \& Aiken, M. 2004. Flaming in electronic communication. Decision Support Systems, 36(3): 205-213.

Anonymous. 1998. To reveal or not to reveal: A theoretical model of anonymous communication. Communication Theory, 8(4): 381-407.

Balnave, N., Barnes, A., Macmillan, C., \& Thornthwaite, L. 2014. E-voice? How network and media technologies are shaping employee voice. In A. Wilkinson, J. Donaghy, T. Dundon, \& R. Freeman (Eds.), The handbook of research on employee voice: 439-454. Cheltenham, UK: Edward Elgar.

Barry, B. 2007. The cringing and the craven: Freedom of expression in, around, and beyond the workplace. Business Ethics Quarterly, 17(2): 263-296.

Barsade, S. G., \& Gibson, D. E. 1998. Group emotion: A view from top and bottom. In M. A. Neale \& E. A. Mannix (Eds.), Research on managing groups and teams, vol. 1: 81-102. Stamford, CT: JAI Press.

Baur, D., \& Arenas, D. 2014. The value of unregulated business-NGO interaction: A deliberative perspective. Business \& Society, 53(2): 157-186.

Beschorner, T. 2006. Ethical theory and business practices: The case of discourse ethics. Journal of Business Ethics, 66(1): 127-139.

Bishop, L., \& Levine, D. I. 1999. Computer-mediated communication as employee voice:

A case study. Industrial and Labor Relations Review, 52(2): 213-234. 
Callison, C. 2001. Do PR practitioners have a PR problem? The effect of associating a source with public relations and client-negative news on audience perception of credibility. Journal of Public Relations Research, 13(3): 219-234.

Cardon, P. W. 2016. Community, culture, and affordances in social collaboration and communication. International Journal of Business Communication, 53(2): 141-147.

Castelló, I., Etter, M., \& Nielsen, F. A. 2016. Strategies of legitimacy through social media: The networked strategy. Journal of Management Studies, 53(3): 402-432.

Castelló, I., Morsing, M., \& Schultz, F. 2013. Communicative dynamics and the polyphony of corporate social responsibility in the network society. Journal of Business Ethics, 118(4): 683-694.

Castells, M. 2007. Communication, power and counter-power in the network society. International Journal of Communication, 1(1): 238-266.

Christensen, L. T., Morsing, M., \& Cheney, G. 2008. Corporate communications. Convention, complexity, and critique. London: SAGE.

Christopherson, K. M. 2007. The positive and negative implications of anonymity in Internet social interactions: "On the Internet, nobody knows you're a dog." Computers in Human Behavior, 23: 3038-3056.

Coombs, W. T., \& Holladay, J. S. 2012. The paracrisis: The challenges created by publicly managing crisis prevention. Public Relations Review, 38(3): 408-415.

Dahlberg, L. 2005. The Habermasian public sphere: Taking difference seriously? Theory and Society, 34: 111-136.

Dawkins, C. 2015. Agonistic pluralism and stakeholder engagement. Business Ethics Quarterly, 25(1): 1-28.

Deetz, S. 1998. Discursive formations, strategized subordination and self-surveillance. In A. McKinlay \& K. Starkey (Eds.), Foucault, management and organizational theory: From panopticon to technologies of self: 151-172. Thousand Oaks, CA: Sage.

Degoey, P. 2000. Contagious justice: Exploring the social construction of justice in organizations. Research in Organizational Behavior, 22: 51-102.

Dempsey, J. 2015. Moral responsibility, shared values, and corporate culture. Business Ethics Quarterly, 25(3): 319-340.

Fraser, N. 1990. Rethinking the public sphere: A contribution to the critique of actually existing democracy. Social Text, 25/26: 56-80.

Garner, J. T. 2009. When things go wrong at work: An exploration of organizational dissent messages. Communication Studies, 60(2): 197-218.

2013. Dissenters, managers, and coworkers: The process of co-constructing organizational dissent and dissent effectiveness. Management Communication Quarterly, 27(3): 373-395.

Goodman, J., \& Arenas, D. 2015. Engaging ethically: A discourse ethics perspective on social shareholder engagement. Business Ethics Quarterly, 25(2): 163-189.

Gossett, M. L., \& Kilker, J. 2006. My job sucks. Examining counterinstitutional web sites as locations for organizational member voice, dissent and resistance. Management Communication Quarterly, 20(1): 63-90.

Grant, A. M. 2013. Rocking the boat but keeping it steady: The role of emotion regulation in employee voice. Academy of Management Journal, 56(6): 1703-1723.

Guthey, E., \& Morsing, M. 2014. CSR and the mediated emergence of strategic ambiguity. Journal of Business Ethics, 120(4): 555-569. 
Habermas, J. 1992. Moral consciousness and communicative action, trans. C. Lenhardt \& S. W. Nicholsen. Cambridge: Polity Press.

1993. Justification and application: Remarks on discourse ethics. Cambridge, MA: MIT Press.

. 1994. The unity of reason in the diversity of its voices. In J. Habermas (Ed.), Postmetaphysical thinking. Political essays: 115-148. Cambridge, MA: MIT Press.

2001a. From Kant's "ideas" of pure reason to the "idealizing" presuppositions of communicative action: Reflections on the detrancendentalized "use of reason." In W. Regh \& J. Bohman (Eds.), Pluralism and the pragmatic turn: Essays in honor of Thomas McCarthy: 11-39. Cambridge, MA: MIT Press.

2001b. The postnational constellation. Cambridge, MA: MIT Press.

Hennig-Thurau, T., Gwinner, K. P., Walsh, G., \& Gremler, D. D. 2004. Electronic wordof-mouth via consumer-opinion platforms: What motivates consumers to articulate themselves on the Internet? Journal of Interactive Marketing, 18(1): 38-52.

Hlavach, L., \& Freivogel, W. H. 2011. Ethical implications of anonymous comments posted to online news stories. Journal of Mass Media Ethics, 26(1): 21-37.

Ho, S. S., \& McLeod, D. M. 2008. Social-psychological influences on opinion expression in face-to face and computer-mediated communication. Communication Research, 35(2): 190-207.

Isaac, M. 2016. How Facebook's fact-checking partnership will work. The New York Times, December 15. https://www.nytimes.com/2016/12/15/technology/facebookfact-checking-fake-news.html.

Kantor, J., \& Streitfeld, D. 2015. Inside Amazon: Wrestling big ideas in a bruising workplace. The New York Times, August 15. https://www.nytimes.com/2015/08/16/ technology/inside-amazon-wrestling-big-ideas-in-a-bruising-workplace.html.

Kassing, J. W. 1997. Articulating, antagonizing, and displacing: A model of employee dissent. Communication Studies, 48(4): 311-332.

. 1998. Development and validation of the organizational dissent scale. Management Communication Quarterly, 12(2): 183-229.

2011. Dissent in organizations. Cambridge: Polity Press.

Kassing, J. W., \& Armstrong, T. A. 2002. Someone's going to hear about this: Examining the association between dissent-triggering events and employees' dissent expression.

Management Communication Quarterly, 16(1): 39-65.

Kassing, J. W., \& DiCioccio, R. L. 2004. Testing a workplace experience explanation of displaced dissent. Communication Reports, 17(2): 111-120.

Kelley, H. H., \& Michela, J. L. 1980. Attribution theory and research. Annual Review of Psychology, 31: 457-501.

Klaas, B. S., Olson-Buchanan, J. B., \& Ward A. K. 2012. The determinants of alternative forms of workplace voice: An integrative perspective. Journal of Management, 38(1): 314-345.

Kling, R., Lee, Y., Teich, A., \& Frankel, M. S. 1999. Assessing anonymous communication in the Internet: Policy deliberations. Information Society, 15(2): 79-90.

Krishna, A., \& Kim, S. 2015. Confessions of an angry employee: The dark side of de-identified "confessions" on Facebook. Public Relations Review, 41(3): 402-410.

Kulik, C. T., Pepper, M. B., Shapiro, D. L., \& Cregan, C. 2012. The electronic water cooler: Insiders and outsiders talk about organizational justice on the Internet. Communication Research, 39(5): 565-591. 
Lankes, R. D. 2008. Credibility on the Internet: Shifting from authority to reliability. Journal of Documentation, 64(5): 667-686.

Lillqvist, E., \& Louhiala-Salminen, L. 2014. Facing Facebook: Impression management strategies in company-consumer interactions, Journal of Business and Technical Communication, 28(1): 3-30.

Lipinski, T. A. 2002. To speak or not to speak: Developing legal standards for anonymous speech on the Internet. Informing Science, 5: 95-111.

Livingstone, S. 2004. Media literacy and the challenge of new information and communication technologies. The Communication Review, 7(1): 3-14.

Lozano, J. M. 2005. Towards the relational corporation: From managing stakeholder relationships to building stakeholder relationships (waiting for Copernicus). Corporate Governance: The International Journal of Business in Society, 5(2): 60-77.

Marwick, A. E., \& Boyd, D. 2011. I tweet honestly, I tweet passionately: Twitter users, context collapse, and the imagined audience. New Media \& Society, 13(1): 114-133.

Marx, G. T. 2001. Identity and anonymity: Some conceptual distinctions and issues for research. In J. Caplan \& J. Torpey (Eds.), Documenting individual identity: The development of state practices in the modern world: $311-327$. Princeton, NJ: Princeton University.

Miceli, M. P., Near, J. P., \& Dworkin, T. M. 2008. Whistleblowing in organizations. New York: Routledge.

Morrison, E. W. 2011. Voice and silence within organizations: Literature review and directions for future research. Academy of Management Annals, 5(1): 373-412.

Nissenbaum, H. 2003. Securing trust online: Wisdom or oxymoron?. In B. E. Koiko (Ed.), Virtual publics: Policy and community in an electronic age: 134-171. New York: Columbia University.

Palazzo, G., \& Scherer, A. G. 2006. Corporate legitimacy as deliberation: A communicative framework. Journal of Business Ethics, 66(1): 71-88.

Rains, S. A. 2007. The anonymity effect: The influence of anonymity on perceptions of sources and information on health websites. Journal of Applied Communication Research, 35(2): 197-214.

Rains, S. A., \& Scott, C. R. 2007. To identify or not to identify: A theoretical model of receiver responses to anonymous communication. Communication Theory, 17(1): 61-91.

Real, K., \& Putnam, L. L. 2005. Ironies in the discursive struggle of pilots defending the profession. Management Communication Quarterly, 19(1): 91-119.

Rosenberry, J. 2011. Users support online anonymity despite increasing negativity. Newspaper Research Journal, 32(2): 6-19.

Salter, M. 2013. Justice and revenge in online counter-publics: Emerging responses to sexual violence in the age of social media. Crime, Media, Culture, 9(3): 225-242.

Scherer, A. G., \& Palazzo, G. 2007. Toward a political conception of corporate responsibility: Business and society seen from a Habermasian perspective. Academy of Management Review, 32(4): 1096-1120.

Scott, C. R. 2004. Benefits and drawbacks of anonymous online communication: Legal challenges and communicative recommendations. Free Speech Yearbook, 41(1): 127-141.

Scott, C. R., \& Rains, S. A. 2005. Anonymous communication in organizations: Assessing use and appropriateness. Management Communication Quarterly, 19(2): 157-197. 
Scott, C. R., Rains, S. A., \& Haseki, M. 2011. Anonymous communication: Unmasking findings across fields. In C. Salmon (Ed.), Communication yearbook, vol. 35: 29-342. New York: Routledge.

Shahinpoor, N., \& Matt, B. F. 2006. The power of one: Dissent and organizational life. Journal of Business Ethics, 74(1): 37-48.

Shoss, M. K., Maurer, A. H., \& Rupprecht, E. A. 2013. "My boss is probably the devil!" Exploring employees' online vents. In W. J. Zerbe, N. M. Ashkanasy, \& C. E. J. Härtel (Eds.), Individual sources, dynamics, and expressions of emotion. Research on emotion in organizations, vol. 9: 249-277. Bingley, UK: Emerald Group Publishing Limited.

Skarlicki, D. P., \& Kulik, C. T. 2005. Third-party reactions to employee mistreatment: A justice perspective. Research in Organizational Behavior, 26: 185-231.

Stahl, B. C. 2005. The responsible company of the future: Reflective responsibility in business. Futures, 37(2/3): 117-131.

Stohl, C., \& Cheney, G. 2001. Participatory processes/paradoxical practices: Communication and the dilemmas of organizational democracy. Management Communication Quarterly, 14(3): 349-407.

Stohl, C., Etter, M., Banghart, S., \& Woo, D. 2017. Social media policies: Implications for contemporary notions of corporate social responsibility. Journal of Business Ethics, 142: 413-436.

Strandberg, K. 2008. Public deliberation goes on-line? An analysis of citizens' political discussions on the Internet prior to the Finnish parliamentary elections in 2007. Javnost - The Public, 15(1): 71-90.

Streitfeld, D., \& Kantor, J. 2015. Jeff Bezos and Amazon employees join debate over its culture. The New York Times, August 17. https://www.nytimes.com/2015/08/18/ technology/amazon-bezos-workplace-management-practices.html.

Suchman, M. C. 1995. Managing legitimacy: Strategic and institutional approaches. Academy of Management Review, 20(3): 571-610.

Surowiecki, J. 2004. The wisdom of crowds. New York: Anchor.

Taras, D., \& Gesser, A. 2003. How new lawyers use e-voice to drive firm compensation: “Greedy associates" phenomenon. Journal of Labor Research, 24(1): 9-29.

Teo, H., \& Caspersz, D. 2011. Dissenting discourse: Exploring alternatives to the whistleblowing/silence dichotomy. Journal of Business Ethics, 104(2): 237-249.

Trieu, R. 2016. How businesses are using anonymous Blind app to change work culture. Forbes Asia, June 2. https://www.forbes.com/sites/rosatrieu/2016/07/02/howbusinesses-are-using-anonymous-blind-app-to-change-work-culture/\#301f562eff81.

Trittin, H., \& Schoeneborn, D. 2015. Diversity as polyphony: Reconceptualizing diversity management from a communication-centered perspective. Journal of Business Ethics. doi:10.1007/s10551-015-2825-8.

UNESCO. 2017. Media and information literacy. http://www.unesco.org/new/en/ communication-and-information/media-development/media-literacy/mil-ascomposite-concept/.

Valentine, S., Fleischman, G. M., Sprague, R., \& Godkin, L. 2010. Exploring the ethicality of firing employees who blog. Human Resource Management, 49(1): 87-108.

Van Laer, J., \& Van Aelst, P. 2010. Internet and social movement action repertoires: Opportunities and limitations. Information, Communication \& Society, 13(8): 1146-1171.

Whelan, G. 2012. The political perspective of corporate social responsibility: A critical research agenda. Business Ethics Quarterly, 22(4): 709-737. 
2013. Corporate constructed and dissent enabling public spheres: Differentiating dissensual form consensual corporate social responsibility. Journal of Business Ethics, 115(4): 755-769.

Whelan, G., Moon, J., \& Grant, B. 2013. Corporations and citizenship arenas in the age of social media. Journal of Business Ethics, 118(4): 777-790.

Young, I. M. 2006. Responsibility and global justice: A social connection model. Social Philosophy and Policy, 23(1): 102-130. 